\title{
Histopathologic study of Liver Tissue from Wistar Albinos Rats Treated with Methanolic Extract of Leptadenia Hastata's Roots
}

\author{
Mama Sy Diallo ${ }^{1 *}$, Fatoumatah $\mathrm{Ba}^{2}$, Chérif Mouhamed Dial ${ }^{3}$, Cheikh Diop ${ }^{2}$, Oumar faye ${ }^{1}$ and \\ Mamadou Fall ${ }^{2}$ \\ ${ }^{1}$ Laboratory of Histology, Embryology and Cytogenetics, Pharmacy and Odonto-Stomatology, University Cheikh Anta Diop, Senegal \\ ${ }^{2}$ Laboratory of Toxicology and Hydrology, Pharmacy and Odonto-Stomatology, University Cheikh Anta Diop, Senegal \\ ${ }^{3}$ Laboratory of Pathology, Pharmacy and Odonto-Stomatology, University Cheikh Anta Diop, Senegal
}

*Corresponding author: Mama Sy Diallo, Laboratory of Histology, Embryology and Cytogenetics Faculty of Medicine, Cheikh Anta Diop Univesrity, Dakar, Senegal.

To Cite This Article: Mama Sy Diallo, Histopathologic study of Liver Tissue from Wistar Albinos Rats Treated with Methanolic Extract of Leptadenia Hastata's Roots. 2020 - 7(6). AJBSR.MS.ID.001209. DOI: 10.34297/AJBSR.2020.07.001209.

Received: 眥 February 05, 2020; Published: 講 March 04, 2020

\begin{abstract}
Introduction: In Senegal, phytotherapy is an important part of traditional medicine and it is important to report the cases with lethal dose in experimental models. Leptadenia Hastata (L. hastata) is a plant that is widely used in Senegalese pharmacopeia and in the rest of the African continent. The aim of the present study was to investigate histopathological changes in liver and kidney after administration of Roots of L. hastata in Wistar Albinos rat, following a protocol of sub-acute toxicity.
\end{abstract}

Material and Methods: Eighteen Wistar Albinos rats were randomly divided into 3 groups, the control group (Group I) and Group II and III that received the methanolic extract of $L$. hastata at doses of $500 \mathrm{mg} / \mathrm{kg} / \mathrm{j}$ and $1000 \mathrm{mg} / \mathrm{kg} / \mathrm{j}$ respectively for 28 days.

Results: Transaminases and Creatinine levels were statistically higher in group II $(\mathrm{P}<0.05)$. The posology of $1000 \mathrm{mg} / \mathrm{kg} / \mathrm{day}$ was lethal at the $16^{\text {th }}$ day of administration. We found lesions such as vacuolar degeneration in the liver and the kidney of rats that received L. hastata at the dose of $500 \mathrm{mg} / \mathrm{kg} / \mathrm{day}$. With an administration of $1000 \mathrm{mg} / \mathrm{kg} /$ day, there were retraction of the floculus in renal tissue and severe hepatic lesions such as marked vacuolar degeneration, inflammation and necrosis.

Conclusion: Methanolic extract of roots of L. hastata were responsible in our study for severe hepatic lesions and was lethal following administration according to a protocol of sub-acute toxicity.

Keywords: Roots of Leptadenia Hastata; Subacute Toxicity; Hepatic Lesion; Phytotherapy

\section{Introduction}

Liver and kidney are vital organ that play an important role of detoxification and biotransformation of drugs and toxins. These organs are major target in safety assessment of preclinical toxicity and in oncogenicity studies with rodents.

Hepatic lesions are often described in phytotherapy and some components can even be responsible for fulminant hepatitis and conduce quickly to death [1] In Senegal, phytotherapy is an important part of traditional medicine and it is important to report the cases with lethal dose in experimental models.
Leptadenia Hastata (L. hastata) is a plant currently used as a remedy in Senegal and in the rest of Africa for a very long time in the past and different uses have been described in the literature as milk drying, trypanosomiasis, acute rhinopharyngitis [2,3]. In veterinary medicine, L. hastata is used to treat horse's colic and has antibacterial and anti-helminthic [4]. According to main studies, L. hastata water extract is relatively safe [5] Neverthless, Maurice suggested that a higher dosage of L. hastata is lethal to rats and could pose a public health problem to human and animal subjects because of prolonged and quantitative consumption. The aim of the present 
study was to investigate histopathological changes in liver and kidney after administration of Roots of L. hastata in Wistar albinos' rat following a protocol of sub-acute toxicity.

\section{Material and Methods}

Our study was conducted at the faculty of Medicine and Pharmacy of Cheikh Anta University of Dakar. This study was carried out thanks to a collaboration between the laboratory of Toxicology, the laboratory of Histology-Embryology-Cytogenetics and the laboratory of Pathology of Cheikh Anta Diop University. The experiment was approved by the Ethics Committee of Cheikh Anta Diop University of Dakar (Senegal).

\section{Preparation of Plant Extract}

Roots of L. Hastata were collected in the Bush, $18 \mathrm{~km}$ far from Dakar in the locality of Sangalcam. The root material was taxonomically identified and authenticated by expert in the unit of botanic at the Pharmacy Faculty of Cheikh Anta Diop University of Dakar. Roots were sectioned, washed, and dried without exposition to sun or dust. Five hundred (500) mg/kg/day. L. hastata roots were turned into smaller pieces with a mixer. The obtained powder was extracted by double maceration with methanol for about seventy-two hours. After filtration, the extract was evaporated using rotary evaporator apparatus and was put in the oven at $40^{\circ} \mathrm{C}$ till complete dryness.

\section{Rats}

Eighteen Wistar rats with eight to twelve weeks old and average weight of 180-220 g were studied. they were raised and kept at the temperature of $22^{\circ} \mathrm{C} 4$ and $12 \mathrm{~h}$ of dark/light cyclic program with free access to food and water.

\section{Sub-acute toxicity study}

The animals were randomly divided into 3 groups $(n=6)$ with equal number of male and female.

a. Group I: The control group, received $2 \mathrm{ml}$ of solution of mineral water containing methanol (10\% of total volume).

b. Group II and III: Received the methanolic extract of $L$. hastata at doses of $500 \mathrm{mg} / \mathrm{kg} / \mathrm{j}$ and $1000 \mathrm{mg} / \mathrm{kg} / \mathrm{j}$ respectively for 28 days.

During this period, all the animals were observed daily for signs of toxicity and mortality. The changes in body weight, food and water intake and clinical signs were recorded.

\section{Histopathologic study}

After necropsy, samples from liver and kidney were obtained and fixed in buffered formalin (10\%) for at least 24 hours. The samples were dehydrated in graded series of ethanol, cleared in $x y-$ lene, embedded in paraffin wax and sectioned at 4-5 $\mathrm{m}$. The slides were stained with the Hematoxylin and Eosin (H\&E Stain). Changes were graded as follows: (0) showing no changes, (1) for mild changes (less than 30\%), (2) moderate changes (more than 30\% and less than 50\%) and (3) for severe changes (more than 50\%), following guidelines from the INHAND Project (International Harmonization of Nomenclature and Diagnostic Criteria for Lesions in Rats and Mice) [6].

\section{Microscopy}

To analyze the slides, we used photonic microscope from Leica (Leica, microsystems, Wetzlar, Germany), DM 750 and Lasez software to capture and store the images.

\section{Biochemical study}

On day 28, after anesthesia, blood samples were taken from the heart of the animal. Serum was obtained for biochemical analysis after centrifugation at $2500 \mathrm{rpm}$ by min for $15 \mathrm{~min}$. The biochemical indices such as aspartate aminotransferase (AST) and alanine aminotransferase (ALT) transaminases were analyzed. They were assessed in the laboratory of Biochemistry in Diamniadio Hospital using diagnostic kits purchased from Roche Diagnostics Ltd (Germany).

\section{Statistical Analysis}

Results of biochemical analysis (transaminases) were expressed as mean \pm standard deviation (SD). The difference between the different groups were compared using test of variance (oneway ANOVA). Differences with values of $p<0.05$ were considered statistically significant. Statistics were performed using GraphPad software.

\section{Results}

\section{Biochemical analysis}

Transaminases levels were elevated in Group II. The biostatistical analysis of the biochemical parameters indicated statistically significant difference in ALT, AST levels between the treated group and the control group. The posology of $1000 \mathrm{mg} / \mathrm{kg} / \mathrm{j}$ was lethal. Indeed, we found rats of Group III, dead on day 17 and 19. We did not take blood sample from them. Results are presented in table 1

Table 1: Effects of $L$. Hastata roots on biochemical parameters after 28 days' treatment.

\begin{tabular}{|c|c|c|}
\hline & Group 1 Control & Group 11 500 mg/kg/day \\
\hline \multicolumn{3}{|c|}{ Males } \\
\hline ALT (UI/L) & $51.33 \pm 0.88$ & $69.64 \pm 5.61^{* * *}$ \\
\hline
\end{tabular}




\begin{tabular}{|c|c|c|}
\hline AST (UI/L) & $125.9 \pm 9$ & $271.6 \pm 10.23^{* * *}$ \\
\hline \multicolumn{2}{|c|}{ Female } & $96,43 \pm 2,23^{* * *}$ \\
\hline ALT (UI/L) & $41,33 \pm 0,58 \quad 141,33 \pm 10,03$ & $161,94 \pm 8,11^{* * *}$ \\
\hline AST (UI/L) & & \\
\hline
\end{tabular}

\footnotetext{
${ }^{* * *}=p<0.001$ vs. control
}

\section{Histology}

Macroscopic examination: In treated group, with the lethal dose of $1000 \mathrm{mg} / \mathrm{kg} /$ day of L. hastata, the aspect of the liver was smooth and regular. The external aspect of the liver was similar in Group I and Group II. In group III, we noted that the liver was smaller and after section the parenchyma was darker than it was in the control group (Figure 1).
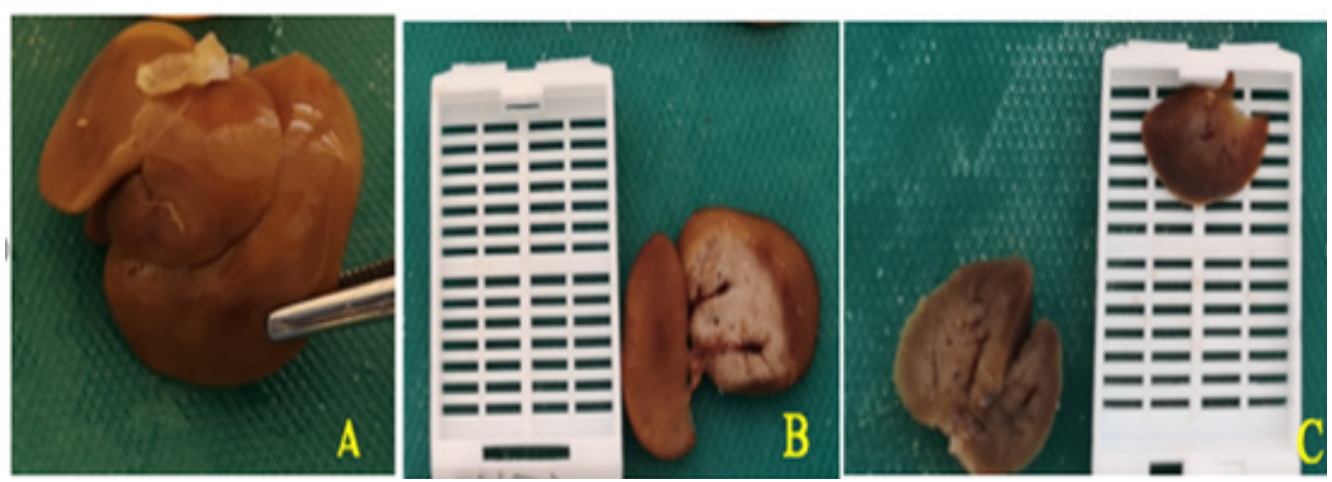

Figure 1: Macroscopic aspect of the liver.

A-External aspect of the liver in control rats.

B- Aspect of the parenchyma of the liver after section in control rats.

C- Dark parenchyma and retracted aspect of the liver in Group III.
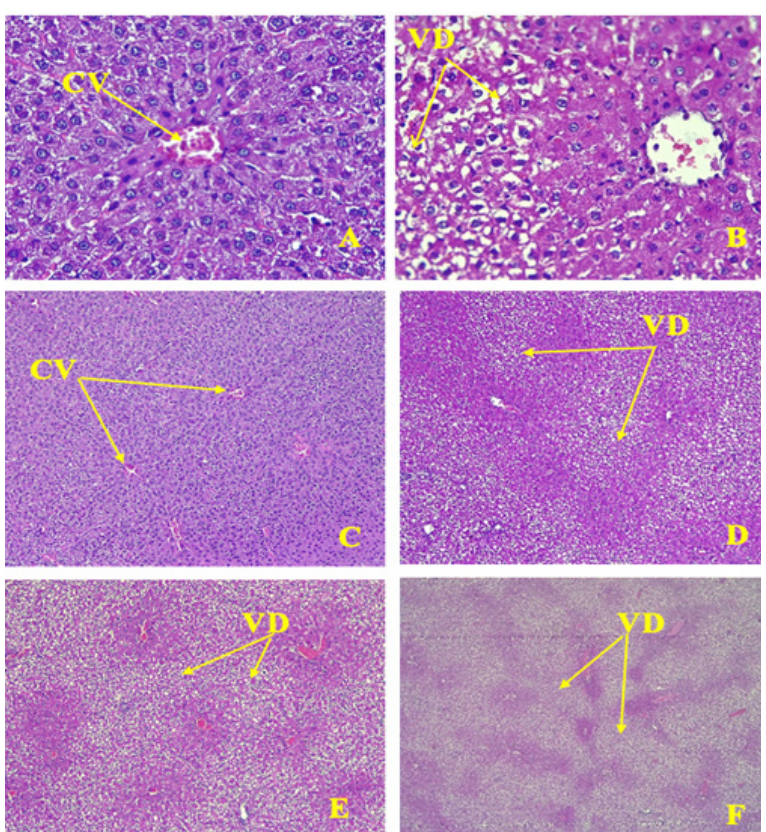

Figure 2: Aspects of vacuolar degeneration.

$\mathrm{CV}=$ Central vein, $\mathrm{VD}=\mathrm{Vacuolar}$ degeneration

A-Liver of rat control; Central vein (CV) with regular cords of hepatocytes (HEX400)

B-Vacuolar degeneration in the mild zone of the lobule while the hepatocytes around the central vein are normal $(\mathrm{HE} X 400)$

C-Liver of rat control (HE X100).

D- Mild vacuolar degeneration in mild zonal and periportal segments in Group II (HE X100).

E- moderate vacuolar degeneration in mild zonal and periportal area (Group II and III) (HE X100).

F- Severe vacuolar degeneration (Group III) (HE X100). 
Microscopy examination: In Group I, the histological structure of the liver was normal with cords of polygonal, regular, hepatocytes. Normal sinusoidal space was noted between the cords. The central vein and portal vein were normal (Figure 2).
In group II and III, the main hepatic lesion was vacuolar degeneration, moderate to severe with a particular topography because it was located in the midzonal segment (Figure 2) and the periportal segment of the hepatic lobule (Figure 3). The results of histopathological changes are summarized in the Table 2.
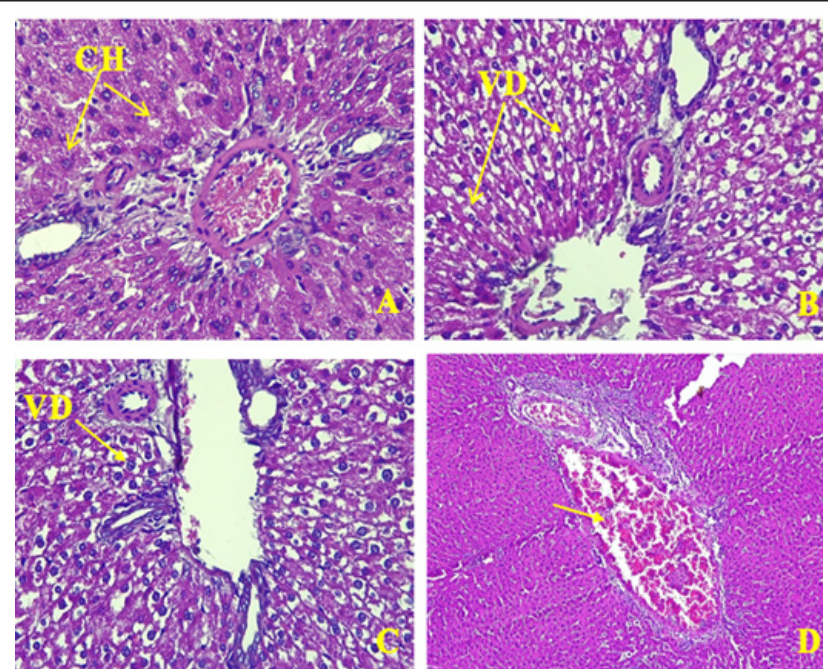

Figure 3: Periportal lesions.

$\mathrm{CH}=$ cords of hepatocytes, $\mathrm{VD}=$ vacuolar degeneration

A-Periportal segment in control rat with normal hepatocytes (HE, X400).

B-Vacuolar degeneration around the portal vein in group II (HE, X200).

C-Vacuolar degeneration around the portal vein in group III (HE, X200).

D-Thrombotic micro angiopathy with plots of fibrin in the portal vein (HE, X200).

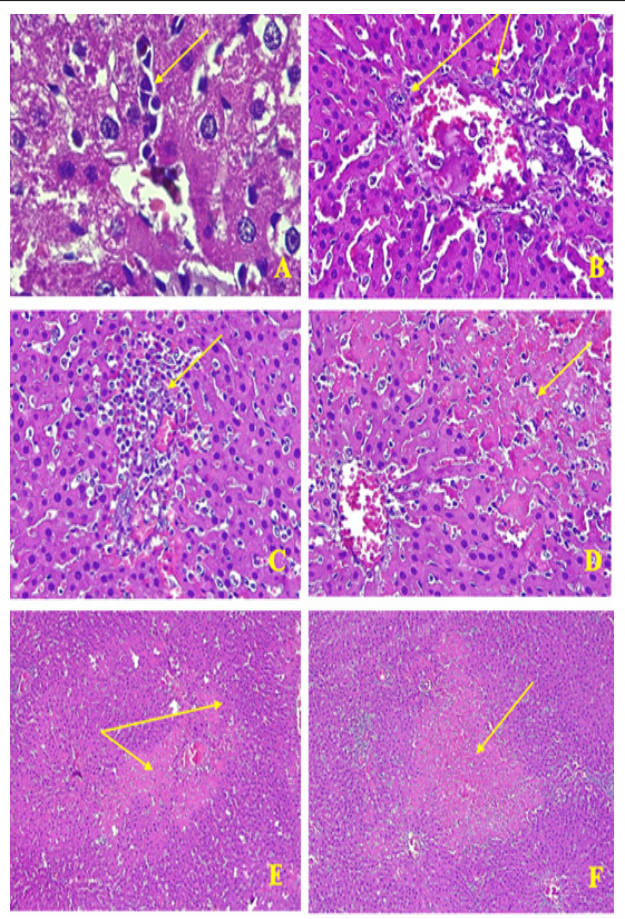

Figure 4: Inflammation and necrosis in the liver.

A-Infiltrate of lymphocyte (HE, X400).

B-Activation of Küpfer cells, aggregate of leucocytes (HE, x400).

C-infiltrate of leucocytes in necrosis foci (HE, x200).

D-Foci of mild lobular necrosis with Karyorrhexis, and hypereosinophilly (HE, x 200).

F-Eosinophilic foci of necrosis disseminated in the parenchyma (HE, x 100).

E-foci of necrosis in a triangular portal lobule shape $(F)$. 
Table 2: Characteristics of Lesions in the Liver and the Kidney in the different groups.

\begin{tabular}{|c|c|c|c|c|}
\hline Hepatic Lesions & Group I (Control) & $\begin{array}{c}\text { Group II 500mg/day of } \\
\text { Leptadenia Hastata }\end{array}$ & $\begin{array}{c}\text { Group III 1000 mg/day of } \\
\text { Leptadenia Hastata }\end{array}$ & Topography \\
\hline Cytoplamic vacuolation & 0 & 1 & 2,3 & Mildzonal and periportal \\
\hline Necrosis & 0 & 0 & 1,2 & Multifocal \\
\hline Microagiopathy & 0 & 0 & 1 & Portal vein \\
\hline Activated Kupferr Cell & 0 & 0 & 2 & $\begin{array}{c}\text { Multifocal, around } \\
\text { necrosis area and in the } \\
\text { periportal segment }\end{array}$ \\
\hline $\begin{array}{c}\text { Inflammation with infiltrate } \\
\text { and aggregates of Leucocyte } \\
\text { and lymphocyte }\end{array}$ & 0 & 0 & & \\
\hline
\end{tabular}

There were also foci of necrotic hepatocytes disseminated in the parenchyma with hypereosinophilly, pyknotic nuclei and karyorrhexis (Figure 4). Actually, Cytoplasm was intensely eosinophilic, especially around the portal tract and nucleus were undergoing lysis.

Some sinusoids were dilated with infiltration of inflammatory cells (Figure $3 \mathrm{~A}$ ), with leucocytes predominantly neutrophil, around dying hepatocytes (Figure 3B) and lymphocyte (Figure 3C). In periportal zone, sinusoids were dilated with activation of Küpfer cells (Figure 4)

\section{Discussion}

\section{Use of the plant}

Leptadenia Hastata is commonly found in West Africa and in Senegal. Healers use the plant for stomachache, hypertension, catarrh, skin disease and trypanosomiasis [7]. Breeders use the leaves and the stems for the treatment of parasites and against placental retention among their animals $[8,9]$. Roots are used in Peulh and Toucouleur pharmacopeia in Senegal to treat lots of diseases such as abdominal complaints [10], and the roots are also used to treat constipation [2], urethral discharge [4] and gonorrhea [3,11]. In Chad, the roots are used to treat scabies [12]. Extracts of Leptadenia hastata were used to study their effect on sickle cell disease and the authors reported in vitro, anti-sickling activity from the methanolic extract of the roots [13].

\section{Hepatic lesions}

The most common lesion we found in the liver was vacuolar degeneration. This lesion was present in all groups that received $L$ Hastata (Group II and in Group III). The lesion was dosage dependent because the degeneration was severe at the posology of $1000 \mathrm{mg} / \mathrm{kg} /$ day and even lethal on day 17 and 20. In this group, the lesions of degeneration were associated with necrosis, angiopathy and inflammation. The vacuolar degeneration was typically midzonal and periportal.

Functionally, periportal cells are more important for glycolysis, lipogenesis, and cytochrome P-450 based drug detoxification, while pericentrolobular hepatocytes are specialized for oxidative liver functions such as gluconeogenesis, ß-oxidation of fatty acids, and cholesterol synthesis. Hepatic necrosis in the periportal zone is observed following a variety of agents (e.g., phosphorus, ferrous sulphate, allyl alcohol) [14] and may be associated with inflammatory [15]. In midzonal zone, some other toxic area also implicated in lesions such as white phosphorus and trichloromethane [16].

Indeed, the topography of the lesion in the hepatic parenchyma is specific for some toxic agents and it would be interesting to evaluate which component in the plant could be responsible for the lesions. L. hastata contains alkaloids, saponins phenolic glycosides, tannins, flavonoids, proanthocyanidins and triterpenes. The plant is usually reported to be safe, nevertheless Maurice [17] insisted in his study that at high dosage, L. hastasta is toxic and lethal at the dose of $1600 \mathrm{mg} / \mathrm{kg} /$ per day. In our study, the posology of $500 \mathrm{~m} /$ $\mathrm{kg} /$ day was responsible for hepatic lesions and the dose of 1000 $\mathrm{mg} / \mathrm{kg} /$ day was lethal. L. hastata was lethal for lower dosage in our study and this may be due to the fact that we used roots and not leaves as it was, in most of publications on the subject.

According to Bayala [18] and Sanda [12], the components in the roots and the leaves are the same but with different proportions. Bayala [18], reported in roots high scores for saponins and flavonoid, low scoring for tannins and ketones and moderate score for alkaloids, while leaves contain higher quantity of saponin and alkaloids, moderate dose of tannins and little dose of flavonoids [12]. This statement could be a scientific base for explaining the therapeutic use of the plant, and the specific utilization of leaves or roots to heal different diseases. Concerning hepatic function, there was cytolysis with elevated rate of ALT. In the literature, we found hepatoprotective effect of leaves extract of L. hastata [19]. Indeed, Extract of $L$. hastata showed promising hepato-protection activity in rats with alcohol-induced liver damage. The histopathological result of that study showed protection in the extract-treated groups when compared with the group that received alcohol alone. Thus, the leaves could be useful in the management of liver diseases. Leaves extract are also reported to be protective on gastric mucosa [20]. 
Our study seems to be the first to emphasis on liver toxicity of methanolic extract of roots of Leptadenia hastata.

\section{Conclusion}

Our study identified liver toxicity of methanol extract roots of L. hastata in Wistar albinos' rats. At the dosage of 1000 mg/ kg per day, the administration was lethal. This plant is described for antibacterial, antifungal, anti-inflammatory, anti-androgenic, anti-diabetic properties. For its contribution in terms of health care treatment in local economies in rural zone in Africa, much attention has to be aid to this medicinal plant. Moreover, benefic effects of roots of $L$. hastata on sickle cell in vitro, deserve further studies to find an adequate dosage or the eviction of its use in this indication.

\section{Competing Interests}

The authors declare that they have no competing interests.References

1. N Webb A, Hardikar W, Cranswick NE, Somers GR (2005) Probable herbal medication induced fulminant hepatic failure. Journal of paediatrics and Child Health 41(9-10): 530-531.

2. African Ethno Botany: Poisons and Drugs. Neuwinger HD (Ed). Chapman and Hall, London, Glasgow, Weinheim, New York, Tokyo, Melbourne, Madras PP. 280-286.

3. (1986) Medicinal Plants in Tropical West Africa. Olivier-Bover BE (Ed), Cambridge University Press, UK pp. 375.

4. Aliero AA, Wara SH (2009) The medicinal potential of Leptadenia hastata. African Journal of pharmacy and pharmacology, Vol 3(6): 335338.

5. Tamboura HH, Bayala B, Lompo M, Guissoe IP, Sawadogo L (2005) Ecological distribution, morphological characteristics and acute toxicity of aqueous extracts of Holarrhena floribunda (G Don), Leptadenia hastata (PERS), decne and cassia sieberiana (DC) used by veterinary healers in Burkina Faso. African Journal of Traditional, Complementary and Alternative Medecines 2(1): 13-24.

6. Keenan CM, Baker J, Bradley A, Goodman DG, Harada T, et al. (2015) International Harmonization of Nomenclature and Diagnostic Criteria (INHAND): Progress to Date and Future Plans. Toxicol Pathol 43(5): 730-732.

7. Dambatta SH, Aliyu BS (2011) A survey of major ethno medicinal plants of kano north, Nigeria, their knowledge and uses by traditional healers. Bayero Journal of Pure and Applied Sciences 4(2): 28-34.

8. Arbonnier (2000) In: M. Arbres (Ed) Arbustes et Lianes des Zones Sèches d'Afrique de l'Ouest. ( $1^{\text {st }}$ edn), CIRAD Publishers, Paris pp. 541.
9. B. Bayala, Telefo PB, Bassole IHN, Tamboura HH, Belemtougri RG, et al. (2011) Anti-spermatogenic Activity of Leptadenia hastata (Pers.) Decne Leaf Stems Aqueous Extracts in Male Wistar Rats. Journal of Pharmacology and Toxicology 6: 391-399.

10. Kerharo J (1967) Senegalese Pharmacopoeia: catalog of medicinal and toxic plants of wolof and Serer, augmented by the mention of common and vernacular names, of properties uses, generally recognized in traditional Medicine. Annales Pharmaceutiques Françaises 25(5): 385438

11. Thomas SD (2012). Leptadenia hastata: A Review of its Traditional uses and its Pharmacological Activity. Medicinal chemistry 2: 148-150

12. Sanda KA, Sandabe UK, Sanda FA, Tijjani MB, Majama YB, et al. (2013) Phytochemical Screening of the Aqueous Root extract of leptadenia hastata (Asclepiadaceae) in Maiduguri, Northern Nigeria. Asian Journal of Biochemistry 8: 33-35.

13. Seck M, Sall C, Gueye PM, Seck I, Dioum MD, et al. (2015) Etude de l'activité antifalcémiante d'extraits de racines de Leptadenia hastata Decne. (Asclepiadacae). International Journal of Biological and Chemical Sciences. 9(3): 1375-1383

14. Atlas of liver pathology 2nd edition (2005) Kanel GC, Korula J (Eds) Los Angeles, California, USA.

15. Ward JM, Yoon M, Anver MR, Haines DC, Kudo G, et al. (2001) Hyalinosis and $\mathrm{Ym} 1 / \mathrm{Ym} 2$ gene expression in the stomach and respiratory tract of 129S4/SvJae and wild-type and CYP1A2-null B6, 129 mice. Am J Pathol 158(1): 323-332.

16. Meegarbane B, Deye N, Baud F (2007) Foie toxique: mécanismes lésionnels et thérapeutiques pharmacologiques spécifiques. Réanimation 16(7-8): 632-642

17. Maurice NA, Garba A, Maina VA, Baraya YS, Owada AH, et al. (2011) Acute Toxicity Effect of the Leaf Extract of Leptadenia Hastata (Pers) in White Albino Rats. Nigerian Journal of Parasitology 32(2): 247-250

18. Bayala B, Halabalaki M, Ouédraogo A, Keiler M A, Tamboura HH, et al. (2018) Leptadenia hastata Pers. (Decne) a Promising Source for Natural Compounds in Biomedical Applications. Am J Drug Discov Dev 8(1): $1-10$.

19. Ojochegbe AB, Adejoh DP, Boniface MT, Duniya SV, Iyaji A (2019) Activity of Methanol Extract of Leptadenia Hastata Leaves in Alcohol-Induced Liver Injury. American Journal of Biomedical Sciences \& Research 4(3).

20. Umaru IJ, Badruddin FA, Umaru HA (2018) Phytochemical, antifungal and antibacterial potential of Leptadenia hastata stem-bark extract. MOJ Toxicol 4(4): 263-268. 